\title{
El diseño flexible en la investigación militante
}

The flexible design in militant research

\author{
Verónica Jaramillo Fonnegra \\ Universidad Nacional de Lanús \\ verojarafonn@gmail.com (ARGENTINA)
}

Recibido: 18.072018

Aceptado: 20.07 .2020

\section{RESUMEN}

El presente escrito se propone recuperar la importancia del diseño flexible de la investigación dentro de la trayectoria de una investigación militante. La intención es demostrar como las distintas técnicas variaron según las necesidades que se fueron presentando en el campo. También pretende recuperar y comprender el lugar en la investigación de quien pretende intervenir por medio de la investigación militante. El objetivo principal del estudio era analizar el acceso a la justicia de las trabajadoras domésticas migrantes en la Ciudad de Buenos Aires entre 2000-2015 y es desde este lugar donde se proponen analizar las técnicas de recolección de información.

\section{PALABRAS CLAVE} ticia.

Investigación militante, diseño flexible, mujeres, migrantes, acceso a la jus-

\begin{abstract}
This paper aims to recover the importance of the flexible design of research within the trajectory of a militant investigation. The intention is to demonstrate how the different techniques varied according to the needs that were presented in the field. It also seeks to recover and understand the place in the investigation of who intends to intervene through militant research. The main objective of the study was to analyze the access to justice of migrant domestic workers in the City of Buenos Aires between 2000-2015 and it is from this place where they intend to analyze the information collection techniques.
\end{abstract}




\section{KEY WORDS}

Militant research, flexible design, women, migrants, access to justice.

\section{INTRODUCCIÓN}

La investigación militante es en la actualidad una herramienta cada vez más utilizada dentro de las ciencias sociales, ya que se reconoce desde las distintas ópticas que "lo personal es político" (Hanisch, 2016). Por ello este tipo de investigación se reconoce como aquella que desde el comienzo de la indagación entiende que no existe una forma neutral de hacer investigación social. La investigación militante es aquella, que utiliza un prisma de análisis y toma una postura sobre el fenómeno, sobre el mundo y que pretende indagar para lograr una transformación, el dato característico de este tipo de investigación es que el método no puede limitar la investigación, sino que a medida que el campo se va transformando la metodología debe ser lo suficientemente flexible para atender a esa trasformación.

En este trabajo se retomarán las distintas transformaciones que sufrió el diseño de una investigación militante realizado a partir del análisis del acceso a la justicia de las trabajadoras domésticas migrantes en la Ciudad Autónoma de Buenos Aires en los inicios del siglo XXI. El marco temporal de la investigación se situó en un periodo de especial confluencia en la región en cuanto a la expansión de los derechos de sectores históricamente excluidos. La Argentina supo liderar varias de las más importantes conquistas, y ahora tiene el desafío de materializar las normas, ya que muchos de estos procesos están inacabados e implican grandes transformaciones culturales. Durante el proceso de elaboración de esta investigación se realizó el seguimiento del antes, el durante y el después de la consagración de una norma y comprender su contexto aporta datos trascendentales para el conocimiento de las construcciones acerca del acceso a la justicia de las trabajadoras domésticas migrantes en la Ciudad Autónoma de Buenos Aires.

Otra de las condiciones indispensables para comprender el acercamiento al tema tienen que ver con la condición de extranjera de la investigadora que pudo experimentar en carne propia las dificultades para acceder a la justicia, por las distintas construcciones culturales y las múltiples formas de ver el mundo, con diferentes modos de expresar el sentir. Esas diferentes formas de concebir el mundo se definen, en gran parte, desde los lugares de poder y desde los de la opresión (Santos, 2009). Por tanto, este análisis de la actuación de las trabajadoras domésticas migrantes ante la justicia sólo podía comprenderse si se visibilizaba que estas vidas transcurrían en la zona del no ser (Grosfogel, 2012); es decir, era necesario evidenciar que las trabajadoras domésticas migrantes históricamente han sido invisibles a los ojos de la sociedad, de las instituciones e incluso de ellas mismas, por lo que están claramente en un lugar de opresión.

Por otro lado, otro de los escenarios que influenciaba el análisis era la pertenencia de la autora a una organización de mujeres migrantes y refugiadas. Donde 
conoció a varias de las primeras entrevistadas. Dicha Asociación también cumplió un importante papel en la primera delimitación del trabajo doméstico como tema de interés analítico, en el año 2009, cuando dentro de la Asociación empezaron los cuestionamientos sobre la ley de "servicio doméstico", ya que varias de las integrantes de la Asociación eran mujeres migrantes militantes barriales que trabajaban en casas particulares.

Dentro de las reuniones las militantes se quejaban permanentemente de las condiciones laborales y del trato de sus empleadoras y empleadores. A veces exponían su descontento y cansancio con las largas jornadas laborales, con el poco dinero que ganaban, con la mala alimentación que recibían o con el mal trato que les daban. Fue por ello que se decidió llamar a un abogado que conocía el tema, para que diera un taller informativo sobre la ley vigente. Después de escucharlo se comprendió la necesidad de un cambio normativo, porque el decreto-ley 326/56 era una norma anacrónica, creada en la dictadura militar de Pedro E. Aramburu.

Al conocer la ley de "servicio doméstico", la organización tomó la decisión con un grupo de compañeras migrantes -militantes barriales, trabajadoras de casas particulares y unas "profesionales voluntarias"1- de llevar adelante un lobby para que se cambiara la ley. Para llevar adelante su acción colectiva fue diseñada una estrategia solidaria entre mujeres de distintas clases sociales. Y en este escenario las mujeres de la organización cuestionaron los símbolos de la cultura imperante y se atrevieron a dotar y proponer un nuevo significado (Melucci, 1988) cuestionando el "marco" (Fraser, 2006) legal que se había creado en 1956 y que debía ser actualizado para garantizar con igualdad de oportunidades los derechos de las trabajadoras del sector.

El punto de partida era pensar que se podía desafiar la idea de que las democracias occidentales delinean subjetividades socio-políticas no participativas (Weckesser, 2010) en las cuales existen amplias dificultades para que las personas "dominadas" puedan oponerse al orden legítimo que se impone (Bourdieu y Passeron 1996). Las mujeres de esta Asociación Civil ya lo habían hecho anteriormente, ya que habían participado políticamente, junto con muchas otras organizaciones de la sociedad civil argentina, en el proceso del cambio de la Ley de Migraciones. Por lo que no dudaron en convocar a una marcha el 18 de diciembre de 2010 (aprovechando la celebración del día del migrante), que culminó con la confección de un petitorio para el Ministerio de Trabajo, Empleo y Seguridad Social (MTESS), y otro para la Presidencia de la Nación solicitando el cambio de ley.

En este contexto, desde la Asociación se convocó a cortar unas calles en el centro de la ciudad para marchar. A la cita concurrieron un pequeño grupo de mujeres migrantes que llevaron dos petitorios a la Casa Rosada y al Ministerio de Trabajo Empleo y Seguridad Social, sin sospechar que un día llamarían

${ }^{1}$ Las profesionales voluntarias, son graduadas de carreras universitarias (abogadas, sociólogas, antropólogas, trabajadoras sociales, etc.) que donan unas horas de su tiempo a la Asociación a la semana. 
para iniciar un dialogo. Los petitorios fueron recibidos respetuosamente y unas semanas después se realizaría una entrevista en la oficina del Ministro de Trabajo. Dentro de la reunión se hablaron de algunos asuntos, como la inclusión de la licencia por maternidad, la Aseguradora de Riesgos del Trabajo (ART) o el reconocimiento de las horas extras, entre otras cosas. Esa primera reunión resultó sorprendente. En principio, por su realización, pero también por el buen trato, la escucha atenta y, sobre todo, por la voluntad política de hablar con un sector "poco significativo" -en términos simbólicos y políticos- para la sociedad argentina.

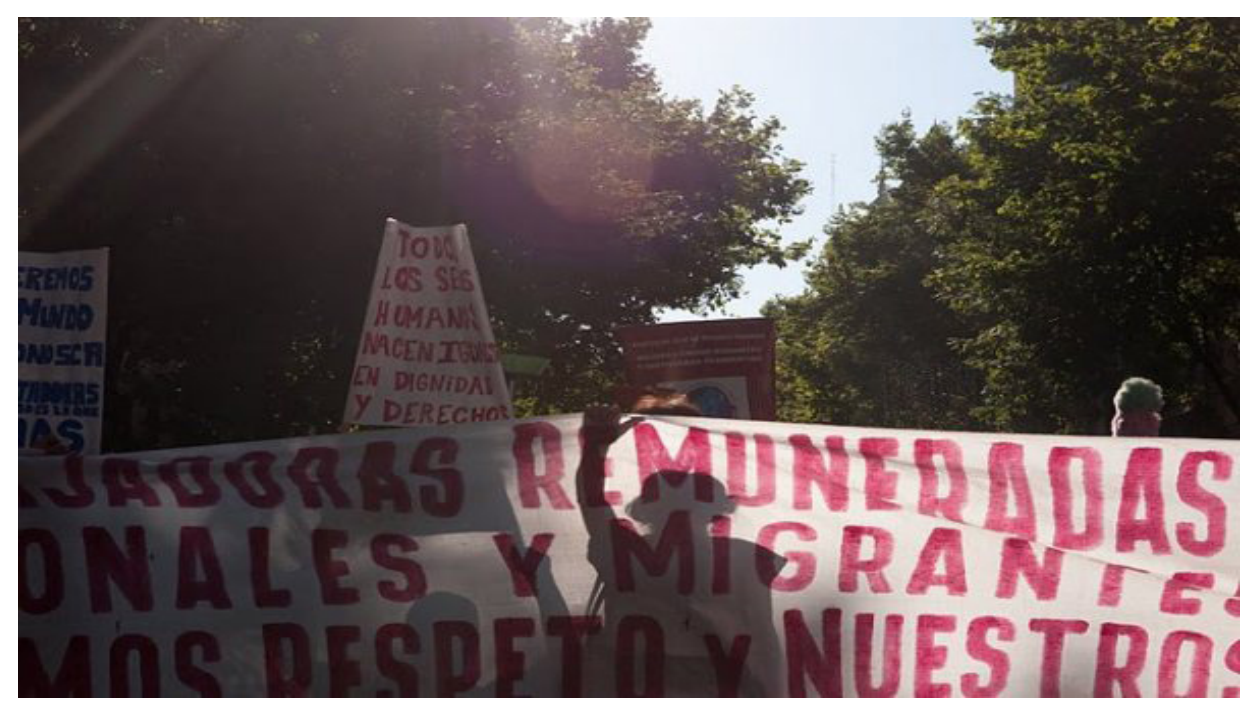

Foto: Marcha 18 de diciembre 2010

Paralelamente, desde otros espacios de militancia también se comenzaban a llevar adelante reclamos y marchas a favor de las trabajadoras del hogar. El principal sindicato, la Unión de Personal Auxiliar de Casas Particulares (UPACP) alineado a la Confederación General del Trabajo (CGT), hizo el llamamiento a participar en el reclamo por los derechos del sector en el verano del año 2010; mediante una movilización donde las trabajadoras sindicalizadas se congregaron en Plaza de Mayo. Si bien la marcha tuvo poco impacto mediático, la importancia simbólica de ocupar los espacios públicos visibilizando una labor "privada" generaban esperanza entre las empleadas en lograr mover la agenda local.

Por su parte, desde la Central de Trabajadores de la Argentina (CTA) también se impulsaron debates, charlas y peticiones para el cambio de ley, las cuales se organizaron en diferentes zonas del país, descentralizando el reclamo que se impulsó desde la capital a los grandes centros urbanos del país. Pero, además, las demandas locales tuvieron eco en la puja internacional por la sanción de una nueva ley para las trabajadoras del sector. 
En ese contexto, y con la idea de impulsar un cambio de la ley de servicio doméstico se decidió participar de una consulta impulsada por la Organización Internacional del Trabajo (OIT) como integrantes de la sociedad civil, ya que por esa época se realizaban las reuniones preparatorias en Ginebra para debatir una nueva norma internacional sobre el trabajo doméstico.

A pesar del contexto de escepticismo sobre la posibilidad de que la norma cambiara, en marzo de 2011 nació la posibilidad de que las cosas empezaran a cambiar. Para el Día de la Mujer convocaron a la Asociación Civil de Mujeres Migrantes junto a cientos de organizaciones feministas a asistir a un acto en la Casa Rosada donde la entonces presidenta, Cristina Fernández, anunciaba que se enviaría un proyecto de ley sobre trabajo en casas particulares al Congreso de la Nación. Hubo una gran emoción y una sensación de que las actividades organizadas desde la Asociación en algo habían contribuido, y que, de concretarse la ley, cambiaría la vida de muchas mujeres.

Una vez se obtuvo el borrador del proyecto de ley, se realizó un trabajo sobre el análisis de su contenido. Durante los más de dos años de debates parlamentarios, el escepticismo permanecía dentro del colectivo migrante, se pensaba que los cambios legales tardarían más tiempo en llegar, ya que consideraba que las trabajadoras domésticas eran un público que carecía del poder de politizar el tema (Fraser, 1989); pero por otro lado consideraba que el momento era el propicio, debido a los debates que se daban también a nivel internacional.

En la OIT la norma se debatió desde el año 2008, para lo cual fueron llamados gobiernos ${ }^{2}$, empleadores y gremios de trabajadoras domésticas, e incluso personas migrantes, a discutir la necesidad de una nueva norma internacional. Desde ese momento la temática fue seriamente considerada parte de la agenda internacional y los representantes de los diferentes países se reunieron con la intención de crear un instrumento internacional para la protección y el trabajo decente del sector, el cual había sido debatido sin éxito desde 1948. En junio de 2011, finalmente se aprobó el "Convenio sobre el trabajo decente para las trabajadoras y los trabajadores domésticos $N^{\circ} 189$ ” de la OIT y a partir de allí, se evidenció el peso de la norma global en el campo jurídico local, ya que es indudable la influencia del Convenio 189/2011 en los debates parlamentarios de la ley de Trabajo en Casas Particulares que se dieron en Argentina entre 2010 y 2013.

Después de aprobada la norma de OIT se insistió y se ejerció presión política en conjunto con otras organizaciones nacionales, en ese contexto se realizaron reuniones, con un asesor de la diputada que estaba encargada de darle impulso al trámite del Proyecto de Ley de Trabajo en Casas Particulares. Después de esta reunión, en diciembre de 2012, pensamos que la Ley perdería estado parlamentario y tendría que ser enviado un nuevo proyecto. Sin embargo, la votación de la ley se dio a comienzos del año 2013. Después de aprobada la ley 26.844 sobre trabajo en casas particulares comenzó un intenso proceso de difusión de

${ }^{2}$ Los debates en la OIT dan cuenta de lo diverso que es el mundo, de las enormes brechas que existen aún entre Oriente y Occidente en la concepción de derechos. 
derechos en el cual se informó las trabajadoras domésticas migrantes de distintos barrios y asentamientos precarios de la Ciudad de Buenos Aires y del Área Metropolitana. Es en ese escenario donde la investigación emerge en un contexto de cambios normativos y confluencias legales y grandes desafíos para las trabajadoras migrantes para hacer cumplir sus derechos.

\section{PRESUPUESTOS EPISTEMOLÓGICOS}

Varios de los presupuestos epistemológicos principales de este estudio refieren a la indagación legal, ya que las normas exponen prácticas sociales y cognitivas donde la política, los intereses personales y de clase tienen un rol protagónico. Es por ello que analizando el contenido de ciertos conjuntos de normas se puede sustraer que la ley acarrea un proceso conflictivo, con elementos ideológicos (Novick, 2008) donde un grupo impone sus intereses materiales y, subyacentemente, su concepción del mundo sobre las demás; para ello, la ley debe convencer y aplicar por diferentes medios la coacción legítima (Novick, 2014). Asimismo, la ley es un "relevante objeto de análisis pues ella resume y transparenta -hace más visibles- aquellos factores llamados genéricamente ideológicos, permitiéndonos aprehender la riqueza y sustancia de la dimensión jurídica de lo social. Dado que la realidad que captamos a través la ley es solo instantánea, necesitamos articular esta perspectiva con un análisis histórico" (Novick, 2014: 19).

El análisis de las normativas impone el desafío de conocer en qué preceptos legales se sustentaban ciertas prácticas sociales y viceversa. Y ya que las normas y el acceso a la justicia se desarrollan en un escenario particular, en un "campo jurídico", es necesario entender su interacción con otros campos sociales. En el campo jurídico se desenvuelven distintas disputas entre agentes e instituciones con distintos niveles de fuerza y capacidades de acción. Todos estos agentes intervinientes operan en el marco de un debate que está jurídicamente reglado con cláusulas "sacramentales" que sólo son conocidas por un público experto, quienes son partes directamente interesadas o son profesionales actuantes en representación de sus clientes (Bourdieu, 2000a). Precisamente, una parte central de este estudio es la de poder comprender las articulaciones entre el campo jurídico y el campo social.

Además de los análisis de los documentos normativos, la interacción con las destinatarias de la norma fue central. Para ello también fue necesario analizar que los presupuestos epistemológicos que advierten a los investigadores e investigadoras de la necesidad de diálogo entre sujeto conocido y sujeto cognoscente, se propuso para ello un diálogo que propiciara, en la medida de lo posible, una interacción en términos de igualdad. También se tuvo en cuenta, un posible equilibrio en el trato entre la investigadora y las investigadas que facilitó el acercamiento a situaciones que eran en principio desconocidas, ya que los sujetos conocidos además de transformar el mundo de la investigadora, transforman su propio mundo al ser investigadas (Vasilachis de Gialdino, 2003). 
En igual sentido, el sujeto cognoscente parte de presupuestos que lo vinculan a nivel emocional y social con su sujeto conocido. $\mathrm{Y}$ al ser la investigadora una mujer inmigrante que investigaba sobre otras mujeres migrantes, el acercamiento y la complicidad surgió entre ellas, en cuestiones como poder retomar la propia experiencia ante las instituciones. Por ejemplo, cuando se trata de apelar a un lenguaje desconocido, el miedo que produce el acercarse a instituciones que son un completo misterio, las dificultades que se tienen para conocer el sistema jurídico local, por las formas de recibir a las personas no nacionales que tienen los sistemas públicos y por las diferentes prácticas burocráticas.

La construcción del campo de investigación surgió entonces desde la empatía, acudiendo a la sociología sentipensante que enseña Fals Borda (2009). Porque las primeras personas en estudio fueron compañeras de militancia, por lo que quizás no había mejor forma de construir el equilibrio entre investigadora e investigadas que estando codo a codo en la lucha. Fue por esta misma razón que las estrategias de investigación quedaron "subordinadas a las lealtades a los grupos actuantes y a las necesidades del proceso" (Fals Borda, 2009: 263).

Tener conciencia "para quién se trabaja" resulta imprescindible en la investigación militante. Conocer "el otro lado" de la historia, el de las empleadoras y empleadores si bien es necesario, permite al mismo tiempo "romantizar" o naturalizar las decisiones de quienes emplean este tipo de trabajo en enormes desigualdades, lo que refuerza las inequidades, se necesita entonces una mirada activa y no neutral del terreno en disputa.

El mayor desafío fue, entonces, desarrollar esta investigación a partir de una meta-epistemología, es decir, una epistemología que contiene la posibilidad de retomar ambas formas de conocimiento: la que parte del sujeto cognoscente usando los postulados científicos tradicionales y la que estudia al sujeto conocido en términos de igualdad (Vasilachis de Gialdino, 2007), sin desconocer que éste último tiene la posibilidad de ser una parte activa en la construcción cooperativa del conocimiento.

\section{LA CONSTRUCCIÓN DE UN MARCO METODOLÓGICO PARA LA ACCIÓN}

El abordaje metodológico elegido fue de corte cualitativo con un diseño flexible, el cual permitió orientar la investigación de acuerdo a los hallazgos que fueron emergiendo, ya que situaciones inicialmente desconocidas llegaron a ser importantes elementos que aportaron validez y fuerza a la investigación. Para ello se usaron estrategias múltiples y complementarias de recolección de datos: análisis documental (de las normativas y los debates parlamentarios), entrevistas individuales (a informantes clave y a las trabajadoras), talleres diagnósticoinformativos (realizados en distintos barrios de la CABA y el Conurbano Bonaerense), observaciones en el Tribunal de Trabajo para el Personal de Casas Particulares, acompañamiento presencial y virtual dirigido a las trabajadoras ante 
distintas instancias de la justicia. El trabajo de campo se realizó entre los años 2011 y 2015.

Durante los primeros años del trabajo de campo fue muy difícil encontrar mujeres migrantes que hubieran judicializado sus problemas con sus empleadores o empleadoras. Éste era un dato en sí mismo, ya que para el comienzo de la investigación se rastreaba poca conciencia entre las mujeres migrantes de la posibilidad de ejercer los derechos en tribunales locales. Aun así, las primeras entrevistas realizadas indagaban sobre trayectorias laborales, percepciones y encuentros con las instituciones de justicia, y también se dispuso de tiempo para responder preguntas sobre la nueva ley de trabajo en casas particulares, con la intención de acercar información privilegiada que podía transformar -aunque fuera un poco- sus vidas.

Una vez percibido el potencial de informarlas, los métodos de indagación comenzaron a cambiar y las entrevistas fueron dejadas de lado. Es decir, solo después de un tiempo se pudo percibir la necesidad de un método que incluyera la acción además del intercambio característico de las entrevistas. Y se propiciaron intercambios grupales o colectivos de aprendizaje de la norma. Esta técnica evidenció que cuando las personas actúan en conjunto se puede comprender que nadie es capaz de "liberarse a sí mismo sin los otros"; (Bhabha, 2013: 78) porque el individuo y el grupo permanecen en la híbrida intersección de los derechos (Gallinati, 2014).

Es decir, en el marco de la investigación se pudo comprender la riqueza del aporte de las experiencias militantes, también denominadas investigación acción participativa (Fals Borda, 1990), investigación militante (Mezzadra y Neilson, 2017) o etnografía activista (Stavenhagen, 2015). Los trabajos de Magdalena León (2013) fueron inspiradores ya que la autora realizó una investigación militante con la que logró modificaciones legales en Colombia. Ella, además, intentó dar respuestas coyunturales a problemas concretos con asistencia jurídica y concientización identitaria a las trabajadoras domésticas. Su método mostró la necesidad de incidir en la vida de sus investigadas y acercarlas a sus derechos.

En la búsqueda de nuevas metodologías de indagación y acción apareció la Red Nacional de Migrantes y Refugiadxs en la Argentina, ${ }^{3}$ y en ese espacio se decidió realizar talleres de diagnóstico en el Área Metropolitana de Buenos Aires (AMBA) con el objetivo de comprender cómo se daba el acceso de estas trabajadoras migrantes a la justicia. Con esa idea se iniciaron los primeros talleres en los distintos barrios carenciados. Después del primer taller se pudo comprender que el desconocimiento de los derechos les impedía a las mujeres reconocerse

${ }^{3}$ La Red Nacional de Migrantes y Refugiadxs en la Argentina se creó después de la aprobación de la Ley de Migraciones, en 2004. Se configuró una coalición que logró nuclear más de 30 organizaciones de la comunidad migrante a nivel nacional; tiene representantes de las colectividades de Bolivia, Ecuador, Perú, Paraguay, Uruguay, Colombia, Venezuela, República Dominicana, Haití, Senegal y Ucrania. Una de sus premisas es la defensa y promoción de los derechos humanos, civiles, políticos, económicos, sociales y culturales de las personas migrantes, refugiadas y sus familias residentes en la República Argentina desde una perspectiva de género, así como el empoderamiento individual, familiar y comunitario. 
como personas con posibilidad de reclamar ante la justicia y poder acceder a ella. Ya que, para el momento del inicio de los talleres, en el año 2014, poco se sabía sobre la nueva Ley de Trabajo en Casas Particulares. Por esta razón, se incorporó a los talleres la dimensión de la acción, materializada en la difusión oral y escrita de información de los derechos laborales adquiridos con la nueva ley. Para estos talleres se prepararon unas cartillas que eran distribuidas entre las mujeres, en donde fueron sintetizadas las normas en un lenguaje claro, incluyendo además direcciones de organismos públicos que les pudieran ayudar.

De un barrio a otro, los talleres variaron en sus características. Los diferentes liderazgos barriales y construcciones de procesos colectivos, gestionaron de distintas maneras la convocatoria a cada taller. En algunos lugares, con menor participación colectiva de los vecinos, la charla se realizó en conjunto con la distribución de una caja de alimentos que gestionaba la Red Nacional de Migrantes y Refugiadxs ante el Ministerio de Desarrollo Social y que era repartida en las diferentes villas y asentamientos del país.

Al principio existía un ruido una molestia por la modalidad de hacer el taller el mismo día en que se entregaba la caja de alimentos. Ya que era posible que muchas mujeres se quedaran a escuchar la charla -participando poco- porque estaban coaccionadas por la entrega de dicha caja. Por ello existía el riesgo de que los intercambios no fueran genuinos y que a las mujeres no les fuera de ayuda o interés. Conforme pasó el tiempo, esta idea fue transformándose. Por un lado, porque se empezó a comprobar de manera directa o indirecta que la información proporcionada les era valiosa. Por otro lado, poniendo la investigación al servicio de las trabajadoras, despejando sus dudas respecto de sus derechos y las formas de reclamar justicia, se encontró información que no aparecía en las entrevistas individuales.

Como se dijo, las dinámicas que se daban en los barrios eran diversas. En algunas charlas no se hablaba mucho y sólo después de escuchar la información sobre los derechos algunas mujeres se decidían a hablar con la investigadora de manera privada o a solicitar el teléfono para un llamado. Así se realizaban conversaciones individuales para analizar cada situación particular. En otros talleres las referentes barriales (casi siempre mujeres migrantes) instaban al cuestionamiento e intentaban encontrar puntos semejantes entre las historias que ellas conocían y la información que se estaba brindando.

Escuchar las experiencias de otras mujeres y reconocer las similitudes, fue fundamental para que algunas migrantes pudieran visibilizar sus problemas. Comprender sus dificultades y potencialidades para acceder a la justicia, las ayudó también a pensar sus límites, sus miedos y sus problemáticas. Así, además de aportar información a una investigación, en esos espacios se configuraron y reconfiguraron sus saberes relativos a los derechos laborales.

Por otra parte, si bien esta investigación se centraba en la problemática de las mujeres migrantes que acceden a la jurisdicción laboral de la Ciudad Autónoma de Buenos Aires (CABA), se decidió no limitar los talleres a los barrios de la CABA porque hay un gran número de trabajadoras que viven por fuera de la ciu- 
dad, pero que trabajaban en ella. ${ }^{4}$ Por lo que resultó indispensable hacer talleres en algunos asentamientos del Conurbano Boanerense.

La forma de aproximación a las trabajadoras de casas particulares migrantes fue entonces desde en diferentes espacios. Después de las charlas diagnósticoinformativas a la investigadora le empezaron a llegar una catarata de mensajes de WhatsApp de mujeres de los diferentes barrios en que se hicieron los talleres. Preguntaban desde cómo se hacía la regularización laboral, hasta cómo contactarse con un abogado para realizar un juicio a sus empleadores. Muchas de ellas fueron acompañadas en los trámites ante el sistema de justicia. Lo que permitió una buena aproximación al proceso de comprensión de la norma, a las formas en que ellas se acercaban a la "ventanilla de la justicia" y a las maneras en que allí eran tratadas.

Después del acompañamiento a varias mujeres por las instituciones públicas se percibió que la presencia en los circuitos burocráticos a veces no resultaba tan beneficiosa porque limitaba la capacidad de acción de la trabajadora y generaba una dependencia con la investigadora. Por ello, se probó una nueva forma de acompañarlas sin estar presente: realizando una comunicación por WhatsApp. Se pretendió, de esa manera, propiciar una forma intermedia entre la soledad en el acceso a las instituciones y la dependencia. A partir de allí, se inició una nueva fase en la investigación la del seguimiento por WhatsApp y por Facebook. En esas instancias virtuales también emergieron varias de las experiencias que se analizan en la investigación.

\section{LAS DISTINTAS TÉCNICAS DE INVESTIGACIÓN Y SUS TENSIONES}

Desde el comienzo de la investigación las técnicas usadas debían ser reevaluadas constantemente, la preocupación por mantener una forma homogénea "prefabricada"(Alonso y Benito, 1998:17) y estructurada estuvo siempre presente, pero el campo, los acontecimientos y las necesidades de las trabajadoras domésticas migrantes transformaron los modos de recabar información y se impuso la necesidad de flexibilizar las técnicas, usando distintos elementos y sirviéndose de los aprendizajes de la militancia. A continuación, se detallan cada una de las técnicas de indagación utilizadas.

\subsection{El análisis con leyes y debates parlamentarios como fuentes documentales}

Los documentos representan en cada sociedad formas específicas y organizadas de pensar, y son una forma de analizar históricamente las transformaciones

${ }^{4}$ Cabe aclarar que lo que finalmente determina la jurisdicción en la que se realiza una demanda es el lugar de trabajo y no donde la trabajadora habita.

EMPIRIA. Revista de Metodología de Ciencias Sociales. N. 48 septiembre-diciembre, pp. 39-66.

ISSN: 1139-5737, DOI/ empiria.48.2020.28070 
del pensamiento y de los conocimientos (Foucault, 2003). Cuando los documentos contienen normas esgrimidas por el Estado, se pueden considerar como una radiografía histórica de dicho Estado y del momento económico y social de un país.

Si bien los documentos jurídicos ofrecen una amplia cantidad de elementos a analizar, "la realidad que podemos captar a través de ellos es instantánea, estática, detenida en un momento del tiempo. Por ello resulta necesario articular su estudio con un análisis diacrónico del contexto económico, político, institucional y demográfico en que se originan" (Novick, 2014: 65). Es decir, para analizar las normas es necesario comprender el contexto de la época en que se sancionaron. Pero también será necesario comprender que los textos jurídicos tienen la capacidad de construir la realidad social y ayudan a proveer a los actores sociales fuentes para interpretar y dirigir la realidad teniendo la capacidad de modificarla (Vasilachis de Gialdino, 1997).

Para dar cuenta de estas transformaciones históricas en el caso argentino en materia de migración y trabajo doméstico, se realizó un análisis documental de: leyes, sentencias y debates parlamentarios. Para comprender cuáles eran los antiguos y nuevos paradigmas normativos y cómo afectaban estas construcciones a la realidad. Este tipo de análisis requiere tener en consideración, especialmente, las leyes en plena vigencia, pero también resultó de gran utilidad estudiar las normas precedentes o derogadas que hacen parte de la inclusión o exclusión institucionalizada que se pueda verificar desde la ley. Conocer y comprender las normas y su impacto en la realidad fue uno de los principales desafíos de este estudio, porque si no existen disposiciones legales que habiliten los derechos a reclamar, no existe el acceso a la justicia. De allí que dichas disposiciones son parte ineludible de la cuestión del acceso a la justicia.

Un documento que ayuda a comprender de manera más completa el contexto de aprobación de la norma es el de los debates parlamentarios. Por tanto, se analizaron los debates parlamentarios sobre la Ley de Trabajo en Casas Particulares, que se desarrollaron entre 2011 y 2013. Allí se estudiaron, especialmente, los factores sociales, políticos y culturales que se tensionan para la construcción de una ley. Para indagar en los debates parlamentarios fue necesario retomar informaciones históricas sobre las condiciones de producción de la norma, no sólo las locales (Carbó, 2001), sino también las que hubiesen podido impactar siendo factores externos o internacionales.

Para realizar este análisis era necesario ver la creación normativa en el contexto en el que se dieron los debates de la ley de trabajo en casas particulares y ya que la Argentina y los países latinoamericanos se encontraban en un momento de expansión y reconocimiento de derechos a grupos históricamente excluidos fue necesario ahondar en este contexto. Especialmente, porque las normas modificadas fueron expedidas durante las dictaduras en la Argentina.

En los años de dictadura se construyeron normativas que des-marcaron (Fraser, 2006) o mantuvieron fuera del marco adecuado a las personas migrantes y a quienes se ocupaban en el trabajo doméstico. Esas normativas estaban basadas en paradigmas machistas, colonialistas y capitalistas (Santos, 2009) que legaliza- 
ron y legitimaron altísimos niveles de informalidad y explotación laboral, lo que redundó en escasas posibilidades de acceder a la justicia laboral. Ello colaboró en la consolidación de representaciones y prácticas sociales que comprendían al - servicio doméstico- como una actividad servil, fácilmente explotable, que no llegaba a ser un trabajo legalmente protegido.

Para el momento histórico de los debates de la ley de trabajo en casas particulares la creación de normas no se daba de forma aislada o local, sino que está inmersa en un macro-sistema consolidado a nivel planetario, se puede entender que los cambios legales nacionales se realizan en consonancia con luchas globales por la consagración de derechos. En efecto, los cambios sobre la ley de trabajo en casas particulares se dieron en coherencia con un proceso global de reivindicación de derechos que, como reconoce Lorena Poblete (2015), se gestó "desde abajo, hacia arriba" en lo que podemos reconocer como un proceso exitoso de cosmopolitismo subalterno (Santo, 2009, García Villegas, 2010). El efecto de las normas internacionales en las argentinas permite dar cuenta, al mismo tiempo, del lugar del país en el sistema mundo/región en ese momento histórico y de su apuesta por ir a la vanguardia en la codificación de nuevas reivindicaciones.

Sin embargo, entre el año 2011 y 2013 esas representaciones fueron debatidas por los y las legisladoras argentinas. El estudio de los debates parlamentarios pretendió exponer el otro lado, el sentir del poder más democrático del país que a su vez es el reflejo social de los empleadores y empleadoras, que, de manera indirecta, dotaron de valiosa información a la investigación. Porque los legisladores y legisladoras pertenecientes a las más altas clases sociales emplean con frecuencia este tipo de trabajadoras; con la gravedad que sus discursos quedan cristalizados en normas. Por otra parte, los debates parlamentarios de ambas Cámaras que se analizaron son testigos de un momento de transición entre las antiguas y las nuevas configuraciones legales.

Si bien los avances de la tecnología permitían almacenar en bases de datos las más de 180 páginas de debates parlamentario para sistematizarlas, se decidió hacer este trabajo de manera artesanal. Con pliegos de papel en los cuales se construyeron celdas con categorías en las que se recortaron fragmentos significativos del texto, las que se ubicaron sistemáticamente en seis pliegos. Esta construcción artesanal permitió de manera visual organizar los temas a los que se les dedicó mayor atención y las distintas miradas según los bloques políticos, para poder distinguir la lucha de los poderes. Por lo anterior, las categorías que se usaron para analizar los debates tuvieron una base histórica y teórica, pero, además, pretendieron indagar en categorías olvidadas por las anteriores normas o retomar discriminaciones establecidas desde la ley.

Dentro de los discursos emitidos se buscó identificar temas ausentes en la ley anterior, por ejemplo, cuántas veces se referían a la extensión de la jornada laboral, a las vacaciones, a la licencia por maternidad, a la necesidad de perpetuar un tribunal independiente fuera de la justicia laboral, al reconocimiento del trabajo doméstico como un verdadero trabajo y el reconocimiento de las mujeres migrantes dentro del espectro de análisis de las trabajadoras del sector. Se buscó 
en estas categorías las posturas concordantes y disonantes y se evaluó el sector político de donde provenían las posturas mayoritarias. Se evidenciaron los puntos en contacto, los acuerdos y los puntos de tensión.

Al momento de analizar los debates parlamentarios se tuvieron en cuenta múltiples elementos, desde la composición étnica, de clase, de género que era bastante uniforme. No existía representación de la diversidad sexual, étnica o racial en el parlamento. De hecho, es importante mencionar que no existe representación de inmigrantes en ninguna de las cámaras para el momento de los debates; ya que no está vigente para ellas la posibilidad de ocupar cargos de elección popular a nivel nacional, es decir, las personas migrantes no cuentan con la opción de hacer escuchar sus reclamos o incluir sus pretensiones dentro de un marco adecuado (Fraser, 2008).

Cabe señalar que en los debates finales no hubo votos negativos; solo hubo ausencias, es decir, legisladores o legisladoras que no asistieron a la votación. Lo que expone de alguna manera una necesidad de modificar la ley. La Cámara Alta del Senado de la Nación en el periodo 2012-2013 tenía 72 integrantes, de los cuales 43 eran varones y 29 mujeres (Cuadro 6). El proyecto de Ley fue votado por un total de 64 senadores y senadoras, con 7 ausencias masculinas y sólo una femenina, lo cual significa que se ausentó el 16,3\% de los varones y el 3,4\% de las mujeres. También se analizaron las ausencias divididas por partido y la cantidad de varones y mujeres dentro de cada uno.

\section{Cuadro 1.}

Ausentismo en la Cámara Alta durante la aprobación del proyecto de Ley de trabajo en casas particulares por frente/partido político y sexo. Argentina. 28 de noviembre de 2012

\begin{tabular}{|c|c|c|c|c|c|c|c|c|c|c|c|}
\hline \multirow{2}{*}{ Frente/Partido Politico } & \multicolumn{4}{|c|}{$\begin{array}{c}\text { Composición de la Cámara Alta por } \\
\text { sexo }\end{array}$} & \multicolumn{4}{|c|}{$\begin{array}{l}\text { Cantidad de Senadores ausentes } \\
\text { por sexo }\end{array}$} & \multicolumn{3}{|c|}{$\begin{array}{l}\text { Porcentaje de ausentismo por } \\
\text { sexo }\end{array}$} \\
\hline & Total & & & Mujeres & Total & Varones & Mujeres & & Total & Varones & Mujeres \\
\hline $\begin{array}{l}\text { Frente para la Victoria } \\
\text { (FPV) }\end{array}$ & & 32 & 17 & 15 & & 1 & 1 & 0 & 3,1 & 5,9 & 0,0 \\
\hline $\begin{array}{l}\text { Unión Cívica Radical } \\
\text { (UCR) }\end{array}$ & & 14 & 12 & 2 & & 2 & 2 & 0 & 14,3 & 16,7 & 0,0 \\
\hline $\begin{array}{l}\text { Federalismo y } \\
\text { Liberación (FyL) }\end{array}$ & & 1 & 1 & 0 & & 1 & 1 & 0 & 100,0 & 100,0 & - \\
\hline $\begin{array}{l}\text { Partido Renovador de } \\
\text { Salta (PRS) }\end{array}$ & & 1 & 1 & 0 & & 1 & 1 & 0 & 100,0 & 100,0 & - \\
\hline $\begin{array}{l}\text { Producción y Trabajo, } \\
\text { San Juan (PyT) }\end{array}$ & & 1 & 1 & 0 & & 1 & 1 & 0 & 100,0 & 100,0 & - \\
\hline $\begin{array}{l}\text { Trabajo y Dignidad } \\
\text { (Chubut) (TyD) }\end{array}$ & & 1 & 0 & 1 & & 1 & 0 & 1 & 100,0 & - & 100,0 \\
\hline Justicia la Pampa (HlaP) & & 2 & 1 & 1 & & 1 & 1 & 0 & 50,0 & 100,0 & 0,0 \\
\hline Otros partidos & & 20 & 10 & 10 & & 0 & 0 & 0 & 0,0 & 0,0 & 0,0 \\
\hline Total & & 72 & 43 & 29 & & 8 & 7 & 1 & 11,1 & 16,3 & 3,4 \\
\hline
\end{tabular}

Por otra parte, y como se observa en el Cuadro 2, el 13 de marzo de 2013 se realizó la votación en la Cámara de Diputados. En el $131^{\circ}$ Período Ordinario en la Primera Sesión de Tablas y en la Primera Reunión, se aprobó el proyec- 
to de Ley por unanimidad con el $100 \%$ de los votos presentes. En el periodo 2012-2013 la Cámara de Diputados tenía 257 integrantes, de los cuales 162 eran varones y 95 eran mujeres. El día de la votación final estuvieron presentes 206 diputados y diputadas, y ausentes 35 varones y 16 mujeres. Es decir, se ausentó el $21,6 \%$ de los varones y el 16,8\% de las mujeres.

\section{Cuadro 2. \\ Ausentismo en la Cámara Baja durante la aprobación de la Ley de trabajo en casas particulares por frente/partido político y sexo. Argentina. 13 de marzo de 2013.}

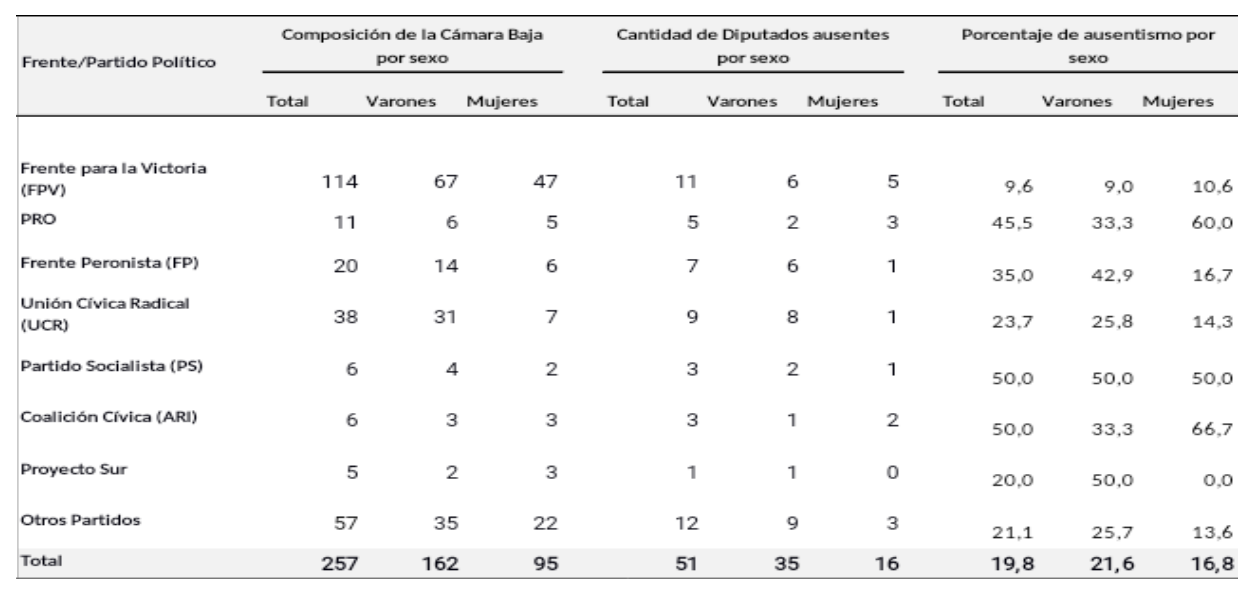

Fuente: elaboración propia con base en http://www.decadavotada.com.ar/

La composición de la Cámara de Diputados al momento de la votación de la Ley de Trabajo en Casas Particulares, expone que las ausencias al debate final estuvieron más representadas por varones. Su adscripción política también fue determinante ya que mientras las mujeres del bloque progresista-oficialista del Frente para la Victoria ${ }^{5}$ (FPV) no faltaron sino en un 10,6\%, las del bloque de centro derecha y principal partido de oposición Propuesta Republicana (PRO) faltaron en un 60\%. Por su parte, los varones faltaron en un 33.3\% los del PRO y un $9 \%$ los del FPV, casi en igual proporción que las mujeres de su bloque. Llamativo fue lo del partido socialista, que, teniendo sólo 6 diputados, asistieron al debate final sólo el 50\% de sus representantes.

Este tipo de análisis, contextual dentro de los debates parlamentarios permitió arribar a distintas conclusiones, por ejemplo, que, a pesar de la alta participación de las mujeres en las sesiones, su sola presencia no es garantía de una mayor incidencia en más y mejores derechos para las trabajadoras. De hecho, se

${ }^{5}$ Fuerza política del Kirshnerismo que para ese momento histórico era del partido mayoritario-oficialista. 
puede ver que son las propias mujeres quienes reconocen la necesidad de cambio de la ley, pero insisten en mantener el régimen de trabajo diferenciado, lo que expone su distancia en términos de clase social respecto de las trabajadoras.

Asimismo, los análisis realizados desde los documentos exponían parte de la realidad, evidenciaban las disputas sociales que desnudaban los privilegios que algún sector de la sociedad no estaba dispuesto a perder, también mostró la escasa incidencia de las trabajadoras domésticas -nacionales y migrante-en los debates. Conocer los debates parlamentarios permitieron al mismo tiempo comprender los discursos dominantes de empleadores y empleadoras que tenían incluso la posibilidad de ser cristalizados como normas, ya que legisladores y legisladoras en general contratan este tipo de servicio. Y si bien los debates parlamentarios pueden entenderse como una toma de posición también puede crear realidades, porque estos discursos se dan en un órgano legislativo que terminó por crear un nuevo marco de derechos, para lo cual era necesario para comprender los terrenos a disputar, para lo cual buscar las voces de las trabajadoras migrantes se hacía necesario.

\subsection{Entrevistas en profundidad a informantes clave y trabajadoras domésticas migrantes}

Los primeros años la investigación doctoral, la militancia permitió la posibilidad de tener contacto con muchas trabajadoras de casas particulares y con algunas personas con trascendentales roles para la aprobación e impulso de la Ley de Trabajo en Casas Particulares. En ese contexto se logró realizar entrevistas al Subsecretario de Políticas Laborales del Ministerio de Trabajo, Empleo y Seguridad Social, a la directora de la Escuela de Capacitación de la Unión de Personal Auxiliar de Casas Particulares (UPACP), a la directora del Tribunal de Trabajo para el Personal de Casas Particulares y a un asesor de la Diputada del Frente para la Victoria que tenía a su cargo el proyecto de Ley de Trabajo en Casas Particulares ante la cámara de Diputados. Los relatos de esas entrevistas a informantes clave no son centrales en el argumento del análisis realizado, pero en algunas ocasiones fueron retomadas para sustentar algunas interpretaciones, también fueron necesarias para comprender los contextos en que se desarrollaron los cambios normativos.

Por otra parte, pese a que la entrevista fue una de las primeras técnicas en ser aplicadas, no sólo por ser la técnica por excelencia cuando se trata de trabajo cualitativo, sino porque el abordaje inicial de la investigación pretendía llevar adelante una tradicional investigación en ciencias sociales, por ello en un primer momento se realizó una guía semi-estructurada que fue aplicada en 9 entrevistas: a 2 mujeres bolivianas, a 4 peruanas y a 3 paraguayas. El diseño de estos instrumentos de recolección de datos (guías de entrevistas), tal como Miles y Huberman (1994) subrayan, no se derivaron solamente de las lecturas bibliográficas, sino de un intercambio entre el bagaje teórico y el contexto de campo. Las entrevistas permitieron en ese contexto, tejer algunas hipótesis y construir otros 
procesos de análisis, así como reafirmar que el concepto de acceso a la justicia que se utilizaría sería uno más amplio que el del mero acceso a la ventanilla judicial. Estas entrevistas fueron incorporadas junto al análisis documental, y especialmente en los capítulo y apartados donde se analizan los efectos de las normas de la dictadura y de las nuevas leyes en las vidas de las mujeres migrantes.

Si bien este tipo de técnica fue prontamente desechada y reemplazada por las charlas diagnóstico-informativas las entrevistas realizadas a mujeres empleadas del hogar fueron fundamentales para comprender las trayectorias laborales y las representaciones individuales que realizaban las mujeres de una idea bastante vaga y lejana de la justicia y de sus posibilidades de acceder a ella. En estas entrevistas el rol de abogada-investigadora terminó siendo central en el abordaje de los intercambios, y, como existía una guía de preguntas, el rol frente a las trabajadoras migrantes marcaba una distancia incómoda, que profundizaba las distancias y dificultaba la empatía. Esta incomodidad surgía principalmente al tener información valiosa para ellas que podía cambiar sus condiciones laborales, información que en el marco de la entrevista no estaba habilitada a proporcionársela, por atentar contra el fin mismo del instrumento.

A continuación, describiré en el cuadro 3 fechas y actores gubernamentales y del sector sindical y subsiguientemente en el cuadro 4 realizaré la lista de las 9 trabajadoras domésticas migrantes (con nombre de fantasía) identificando edad, lugar de nacimiento (identificando su procedencia urbana o rural), estado civil, cantidad de hijos, cantidad de años residiendo en la Argentina, su situación migratoria, el tipo de labores que realizaba y la modalidad laboral en la que trabajaba con la cantidad de horas semanales que trabaja.

Cuadro 3.

Entrevistas individuales a funcionarios públicos o dirigente sindicales

\begin{tabular}{|c|c|}
\hline \multicolumn{2}{|l|}{ Informantes clave } \\
\hline Cargo & Fecha de la entrevista \\
\hline $\begin{array}{l}\text { Subsecretario de Relaciones Laborales del Minis- } \\
\text { terio de Trabajo, Empleo y Seguridad Social }\end{array}$ & Mayo 2013 \\
\hline $\begin{array}{l}\text { Directora de la escuela de oficio del Sindicato } \\
\text { Unión de Auxiliar en Casas Particulares UPACP }\end{array}$ & Noviembre de 2011 \\
\hline $\begin{array}{l}\text { Presidenta del Tribunal de Trabajo para el Perso- } \\
\text { nal de Casas Particulares }\end{array}$ & Agosto de 2014 \\
\hline $\begin{array}{l}\text { Funcionaria del Tribunal de Trabajo para el Perso- } \\
\text { nal de Casas Particulares }\end{array}$ & Octubre 2014 \\
\hline $\begin{array}{l}\text { Asistente de la Senadora Nacional- encargada del } \\
\text { Proyecto de Ley Trabajo en Casas particulares }\end{array}$ & Diciembre 2012 \\
\hline
\end{tabular}




\begin{tabular}{|c|c|c|c|c|c|c|c|}
\hline \multirow{10}{*}{ 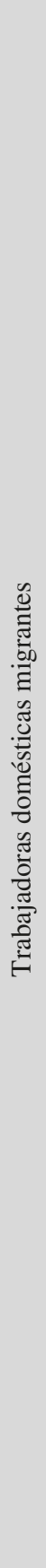 } & 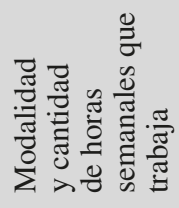 & 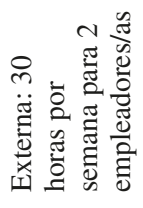 & 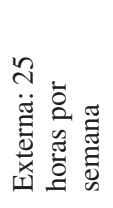 & 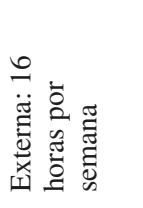 & 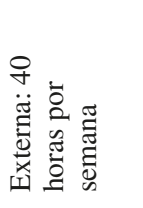 & 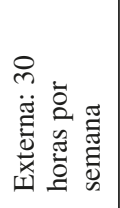 & 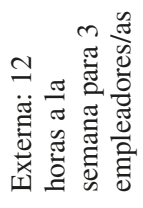 \\
\hline & 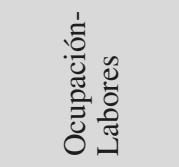 & 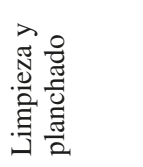 & 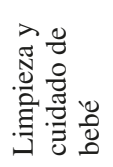 & 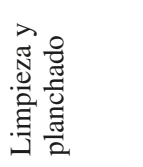 & 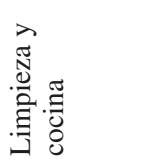 & 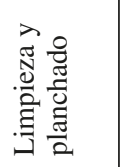 & 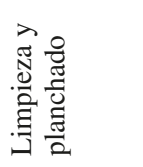 \\
\hline & 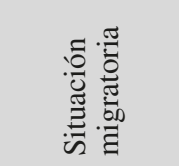 & 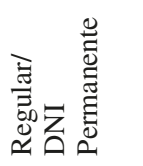 & 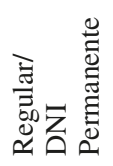 & 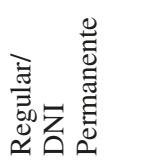 & 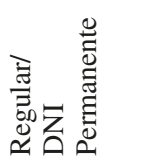 & 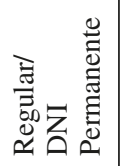 & 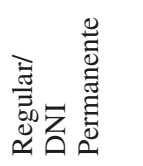 \\
\hline & 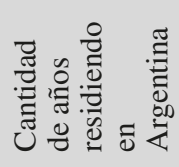 & 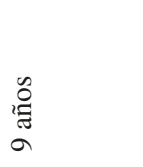 & 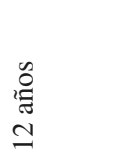 & $\begin{array}{l}\mathscr{0} \\
\text { ఏే } \\
\infty\end{array}$ & 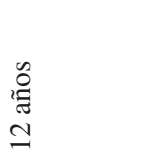 & 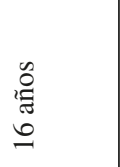 & 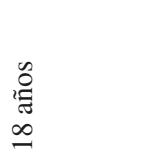 \\
\hline & 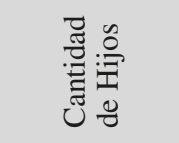 & - & $\sim$ & - & $\sim$ & $\sim$ & - \\
\hline & 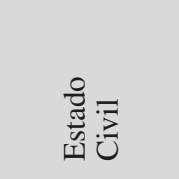 & 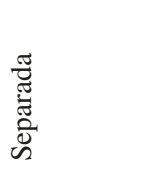 & 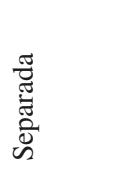 & 㓙 & 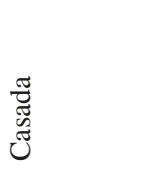 & 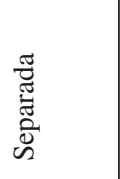 & 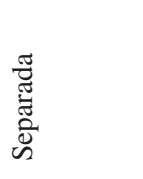 \\
\hline & 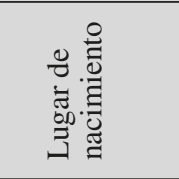 & 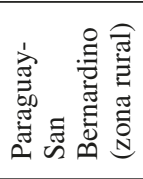 & 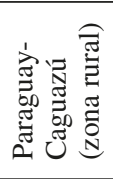 & 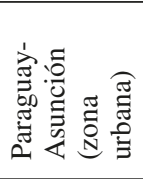 & 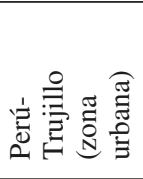 & 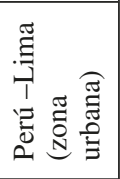 & 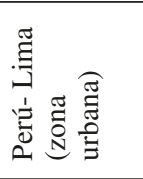 \\
\hline & 疍 & तె & $\stackrel{\infty}{m}$ & ৯े & 焉 & $q$ & กี \\
\hline & 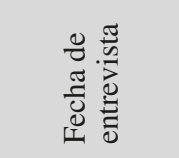 & 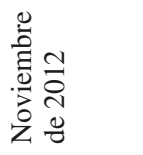 & 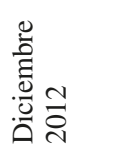 & 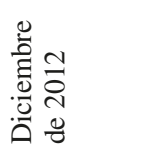 & $\begin{array}{l}\stackrel{0}{0} \\
\stackrel{0}{0} \\
\stackrel{0}{0}\end{array}$ & 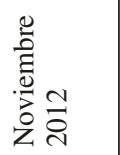 & 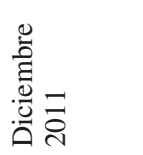 \\
\hline & 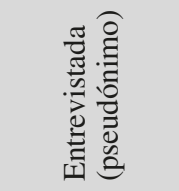 & : & $\begin{array}{l}\frac{\pi}{0} \\
\frac{0}{5} \\
\text { a }\end{array}$ & 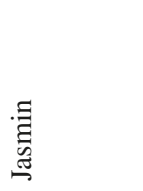 & 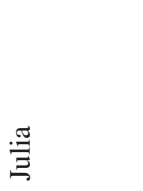 & 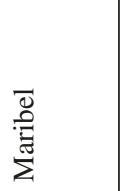 & 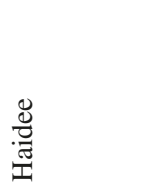 \\
\hline
\end{tabular}




\begin{tabular}{|c|c|c|c|}
\hline 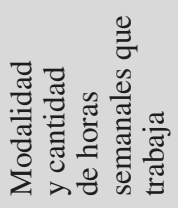 & 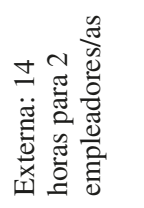 & $\begin{array}{l}\frac{\tilde{T}}{0} \\
\frac{\tilde{\Xi}}{ \pm}\end{array}$ & 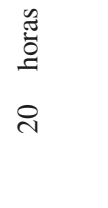 \\
\hline 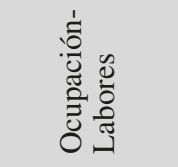 & 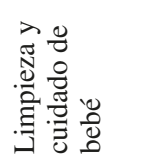 & 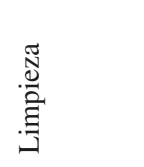 & 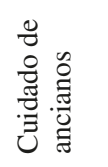 \\
\hline 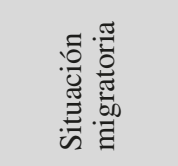 & 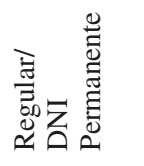 & 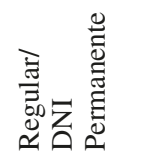 & 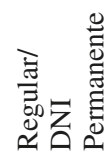 \\
\hline 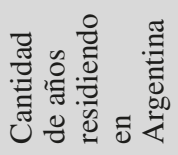 & $\begin{array}{l}\mathscr{0} \\
\text { 壱 } \\
\infty\end{array}$ & 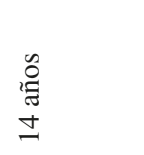 & 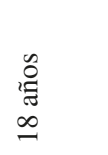 \\
\hline 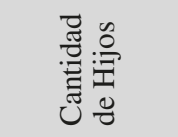 & - & $\sim$ & $m$ \\
\hline 苞: & 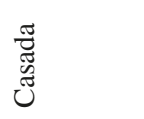 & 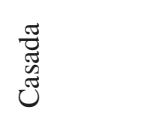 & 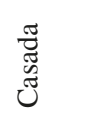 \\
\hline 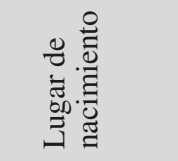 & 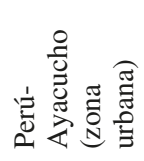 & 离。 & 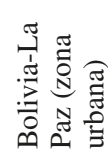 \\
\hline$\underset{\tilde{I}}{\tilde{I}}$ & $\bar{m}$ & ભે & \& \\
\hline 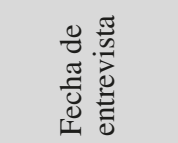 & 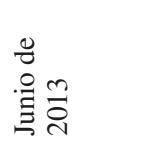 & 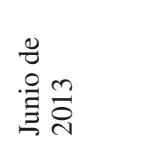 & 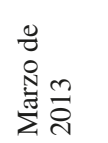 \\
\hline 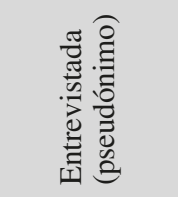 & 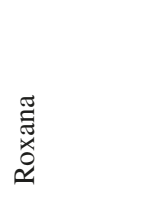 & $\begin{array}{l}\frac{\pi}{0} \\
\frac{0}{0} \\
0 \\
0\end{array}$ & 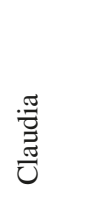 \\
\hline
\end{tabular}

EMPIRIA. Revista de Metodología de Ciencias Sociales. N. 48 septiembre-diciembre, pp. 39-66. ISSN: 1139-5737, DOI/ empiria.48.2020.28070 


\subsection{Talleres diagnóstico-informativos}

Como se dijo, otra de las formas de recopilar información fueron los talleres diagnóstico-informativos que se realizaron en diferentes barrios. Aproximadamente unas 190 mujeres participaron en los talleres, distribuidos en 10 barrios diferentes. Cuatro eran barrios de la Ciudad de la Autónoma de Buenos Aires: Rodrigo Bueno, Villa 31- Retiro, Villa 1-11-14 y Villa Soldati. Y seis barrios del Conurbano Bonaerense, en Lanús, Almirante Brown, José C. Paz, Lomas de Zamora, Moreno, y Florencio Varela. En el cuadro 5 se señala la fecha y la cantidad de participantes en cada taller.

En estos talleres, en un primer momento se compartían experiencias sobre las situaciones que las trabajadoras vivían en sus trabajos y posteriormente retomando algunos de los casos mencionados se realizaba una capacitación que les enseñaba acerca de la nueva ley. El encuadre de estos espacios surgía desde el lugar de abogada-investigadora. Y las participantes asociaban sus dificultades en el acceso a la justicia con la posibilidad tener el contacto de una abogada frente a un posible litigio por lo que había animo de escucha e interés por guardar el contacto. Fue por ello que a muchas de las mujeres asistentes a los talleres se comunicaron posteriormente buscando asistencia legal, bien fuera de manera virtual, o solicitando acompañamiento en el tránsito por las rutas ante las instituciones públicas para reclamar sus derechos laborales.

Con los talleres diagnóstico-informativos se pudo conocer las trayectorias de muchas mujeres ante las instituciones, en particular los aspectos comunes entre ellas. Se comprendieron muchos de los mitos y los relatos construidos comunitariamente, y se conocieron algunos de los circuitos de información que transitaban para conocer sus derechos y acceder a las instituciones, previamente a llegada a la ventanilla de la justicia. Estos eran elementos indispensables para construir un análisis sobre el acceso a la justicia, en dos de sus elementos principales: 1. Cómo las trabajadoras migrantes conocen sus derechos, 2. Como analizan estas mujeres que el sistema jurídico-institucional procesa sus demandas. Todos los talleres fueron grabados en formato audio, aunque como los mismos se llevaron a cabo en lugares abiertos, algunos no tienen buena calidad. No obstante, de cada actividad se tiene un registro escrito, a manera de diario de campo. 


\section{Cuadro 5}

Talleres diagnóstico-informativos

\begin{tabular}{|l|l|l|}
\hline \multicolumn{1}{|c|}{ Barrio } & \multicolumn{1}{c|}{ Fecha de asistencia } & \multicolumn{1}{c|}{$\begin{array}{c}\text { Mujeres partici- } \\
\text { pantes }\end{array}$} \\
\hline Moreno & 13 de abril de 2014 & 16 \\
\hline $\begin{array}{l}\text { Almirante } \\
\text { Brown }\end{array}$ & 25 de mayo de 2014 & 18 \\
\hline José C. Paz & 14 de junio de 2014 & 25 \\
\hline $\begin{array}{l}\text { Lomas de Za- } \\
\text { mora }\end{array}$ & 28 de junio de 2014 & 13 \\
\hline Villa Soldati & 10 de julio de 2014 & 15 \\
\hline Villa 31- Retiro & 28 de agosto de 2014 & 26 \\
\hline Villa 1-11-14 & 21 de septiembre de 2014 & 31 \\
\hline Rodrigo Bueno & 15 de octubre de 2014 & 15 \\
\hline Barrio Pampa & 25 de abril de 2015 & 9 \\
\hline Florencio Varela & 10 de septiembre de 2015 & 190 \\
\hline $\begin{array}{l}\text { Total : 10 ba- } \\
\text { rrios }\end{array}$ & $\begin{array}{l}\text { Entre abril de 2014 y septiembre de } \\
2015\end{array}$ & \\
\hline
\end{tabular}

La información obtenidos a través de esta técnica grupal estaba condicionada por el contexto macro el de las fuerzas sociales y políticas que ya había relevado dentro de los debates parlamentarios. Pero también por los componentes microsociales, como los de las distintas organizaciones barriales que facilitaba los espacios para la realización de los encuentros y extendía la invitación a quienes finalmente serán las participantes de los talleres, el conocimiento del territorio por parte de las referentas migrantes y de sus necesidades la forma de invitación, las contraprestaciones ofrecidas, el local de reunión, el tipo de dinámica grupal (IOE,2010) si las mujeres se conocían o no hacía que fluyera mejor el grupo diagnóstico-informativo.

\subsection{Observaciones presenciales y virtuales}

Después de los talleres diagnóstico-informativos la estrategia de quedar al "servicio" de las trabajadoras había surtido su efecto. Varias de ellas se comunicaron con dudas sobre su relación laboral y otras reclamaron sus derechos con la información proporcionada. Hubo varias trabajadoras que renunciaron o fueron despedidas después del reclamo de sus derechos. Para ese momento histórico, 
pasado un año de la aprobación de la ley, había poca información tanto para trabajadoras como para empleadoras y empleadores. También había pocas herramientas del Estado para contener las demandas de información. Fue por ello que se realizó un acompañamiento por las instituciones para buscar respuestas a sus necesidades. Trabajadoras e investigadora transitaron por lugares como el Tribunal de Trabajo para el Personal de Casas Particulares, el Consultorio Jurídico de la Universidad de Buenos Aires, el Sindicato UPACP e incluso a oficinas de abogados. Con algunas se realizaron acciones judiciales, desde cartas documento a sus empleadores hasta demandas ante el Tribunal. Este lugar en la investigación sirvió para comprender de cerca las distintas trayectorias de acceso a la justicia (Begala y Lista, 2002).

En el cuadro 6 se detallan estas observaciones presenciales, en las que se intentó captar las prácticas asociadas a acontecimientos vividos por las mujeres migrantes y los significados que ellas otorgaban a lo que sucedía con sus pedidos de justicia. Finalmente, se consideró útil la mirada que desde la etnografía se le da a este tipo de aprendizajes, con el fin de captar el significado de las acciones y los acontecimientos de las personas que se estudian (Spradley, 1979).

Así, para poder aprovechar los elementos que la investigación aportaba en ese momento se retomaron algunas de las características del análisis etnográfico básico que incluye elementos como: a) la reflexividad, que lleva a describir una situación para construirla entre quien investiga y quien es investigado; b) el trabajo de campo, en donde existe una forma particular de estar, de manera más prolongada, lo que requiere además de la observación, la interacción y la interpelación, la participación en distintas actividades que se despliegan en la vida cotidiana de quienes se investiga; c) agudizar la mirada; d) consolidar el diálogo, y e) afinar la capacidad de registrar los sucesos que serán elementos indispensables para este tipo de investigación (Ameigeiras, 2006).

Al realizar distintitos tipos de acompañamiento, unas 10 trabajadoras se decidieron a realizar reclamos judiciales, las cuales con mayor o menor éxito cristalizaron sus miedos, las injusticias y las enormes dificultades del paso por las instituciones que experimentan mujeres migrantes de sectores populares. Mientras las trabajadoras lograban traspasar las barreras simbólicas y materiales para reclamar sus derechos, sus empleadores y empleadoras también tejían sus estrategias para no pagar lo que la norma imponía.

El camino en la búsqueda de patrocinios jurídicos y de "acuerdos laborales" justos, o al menos conforme a la ley fueron largos y dolorosos. No existía un cuerpo de abogadas o abogados que pudiera patrocinarla en las causas de forma gratuita. En el Tribunal de Trabajo en Casas Particulares insistían mucho que era mejor un mal arreglo que un buen pleito y esto jugaba poderosamente en la cabeza de las trabajadoras quienes con mucha necesidad perdían grandes sumas de dinero para no tener que esperar mucho. Los abogados y abogadas de los empleadores y empleadoras jugaban con el tiempo y la necesidad de estas mujeres. El contexto en el que se hacían las audiencias era muy doloroso para las trabajadoras, en el Tribunal los llamaban "divorcios laborales" por la especial ruptura que significaba denunciar a su empleadora o empleador por incumplimiento de la 
ley laboral vigente. Sentir que se estaba traicionando a quien te dio la mano, fue el sentimiento constante entre las trabajadoras migrantes y lo que desincentivó a muchas de las que pretendían iniciar una denuncia laboral. El afecto y la cercanía propio de este tipo de relaciones laborales, actúa como una gran limitante y condicionante a la hora de realizar los reclamos por los derechos.

\section{Acompañamiento presencial y observación en instancias estatales}

\begin{tabular}{|c|c|c|c|c|}
\hline \multicolumn{5}{|c|}{ Acompañamiento presencial y observación en instancias estatales } \\
\hline $\begin{array}{l}\text { Pseudónimo- } \\
\text { País de } \\
\text { nacimiento }\end{array}$ & $\begin{array}{l}\text { Espacio } \\
\text { al cual se } \\
\text { acompañó }\end{array}$ & $\begin{array}{l}\text { Tiempo } \\
\text { que duró el } \\
\text { acompañamiento }\end{array}$ & $\begin{array}{l}\text { Causa del } \\
\text { acompañamiento }\end{array}$ & $\begin{array}{l}\text { Observaciones } \\
\text { realizadas en } \\
\text { ese marco }\end{array}$ \\
\hline Taina-Perú & Tribunal & Un mes & Despido injusto & $\begin{array}{l}\text { Concilió por el } \\
65 \% \text { de lo que } \\
\text { le correspondía }\end{array}$ \\
\hline $\begin{array}{l}\text { Solange- } \\
\text { Paraguay }\end{array}$ & Tribunal & Tres meses & $\begin{array}{l}\text { Trabajo no } \\
\text { registrado y } \\
\text { despido injusto }\end{array}$ & $\begin{array}{l}\text { Concilió por el } \\
40 \% \text { de lo que } \\
\text { le correspondía }\end{array}$ \\
\hline $\begin{array}{l}\text { Carmina- } \\
\text { Paraguay }\end{array}$ & $\begin{array}{l}\text { Sindicato / } \\
\text { Tribunal/ } \\
\text { Consultorio } \\
\text { jurídico } \\
\text { UBA/ } \\
\text { Oficina del } \\
\text { abogado }\end{array}$ & Un año & $\begin{array}{l}\text { Trabajo no } \\
\text { registrado, } \\
\text { despido injusto }\end{array}$ & $\begin{array}{l}\text { Inició } \\
\text { demanda, } \\
\text { concilió por el } \\
70 \% \text { después } \\
\text { de un año }\end{array}$ \\
\hline $\begin{array}{l}\text { Celeste- } \\
\text { Paraguay }\end{array}$ & Tribunal & Una semana & $\begin{array}{l}\text { Renuncia por } \\
\text { cambio de } \\
\text { vivienda del } \\
\text { empleador }\end{array}$ & $\begin{array}{l}\text { No pudo } \\
\text { reclamar- }\end{array}$ \\
\hline Ximena-Perú & Tribunal & Una semana & Renuncia & $\begin{array}{l}\text { No pudo } \\
\text { reclamar }\end{array}$ \\
\hline Doris-Peruana & Tribunal & Seis meses & $\begin{array}{l}\text { Solicitud de } \\
\text { aguinaldo }\end{array}$ & $\begin{array}{l}\text { Confección } \\
\text { de un contrato } \\
\text { tramposo a } \\
\text { favor de la } \\
\text { empleadora en } \\
\text { el Tribunal }\end{array}$ \\
\hline $\begin{array}{l}\text { Pseudónimo- } \\
\text { País de } \\
\text { nacimiento }\end{array}$ & $\begin{array}{l}\text { Espacio } \\
\text { al cual se } \\
\text { acompañó }\end{array}$ & $\begin{array}{l}\text { Tiempo } \\
\text { que duró el } \\
\text { acompañamiento }\end{array}$ & $\begin{array}{l}\text { Causa del } \\
\text { acompañamiento }\end{array}$ & $\begin{array}{l}\text { Observaciones } \\
\text { realizadas en } \\
\text { ese marco }\end{array}$ \\
\hline
\end{tabular}




\begin{tabular}{|l|l|l|l|l|}
\hline $\begin{array}{l}\text { Marta- } \\
\text { Paraguay }\end{array}$ & $\begin{array}{l}\text { Tribunal y } \\
\text { Oficina de } \\
\text { abogado }\end{array}$ & Dos meses & $\begin{array}{l}\text { Solicitud a la } \\
\text { registración y } \\
\text { reconocimiento } \\
\text { de la antigüedad }\end{array}$ & $\begin{array}{l}\text { Despido } \\
\text { después del } \\
\text { reclamo, }\end{array}$ \\
\hline Julia- Perú & $\begin{array}{l}\text { Tribunal / } \\
\text { sindicato/ } \\
\text { Oficina de } \\
\text { abogado }\end{array}$ & Ocho meses & Despido injusto & $\begin{array}{l}\text { Pago del 50\% } \\
\text { de lo que le } \\
\text { correspondía }\end{array}$ \\
\hline Haydee- Perú & $\begin{array}{l}\text { Tribunal/ } \\
\text { sindicato }\end{array}$ & Año y medio & $\begin{array}{l}\text { Solicitud de } \\
\text { registración }\end{array}$ & $\begin{array}{l}\text { Blanqueo y } \\
\text { deterioro de } \\
\text { la relación } \\
\text { laboral meses } \\
\text { después } \\
\text { despido }\end{array}$ \\
\hline $\begin{array}{l}\text { Helena- } \\
\text { Paraguay }\end{array}$ & Tribunal & Una semana & Renuncia & $\begin{array}{l}\text { Pago y } \\
\text { acuerdo 100\% } \\
\text { de lo que } \\
\text { correspondía }\end{array}$ \\
\hline
\end{tabular}

\subsection{Acompañamiento virtual:}

Por otra parte, si bien el trabajo de campo con las mujeres en los barrios fue amplio, la virtualidad de las redes sociales se presentó como otra de las formas de hacer etnografía. En la actualidad la etnografía virtual resulta de gran provecho ya que es una forma de comunicación, interacción y reunión (Hine, 2000). Fue por ello que el uso del teléfono celular se fue configurando como una herramienta vital para el desarrollo de la investigación. Varios autores han coincidido que el internet "es un lugar rico en interacciones sociales donde la práctica, los significados y las identidades culturales se entremezclan a través de diversas vías. Las formas de relación social en el escenario virtual suponen un reto para los investigadores sociales y abren nuevos campos para el análisis en el terreno de la metodología cualitativa" (Domínguez Figaredo et al., 2007).

Analizar esta información virtual se presentó en principio como un reto, pero poco a poco se descubrió que este tipo de interacción se realizaba con mujeres que estaban prontas a judicializar su situación, es decir, quienes buscaban ayuda virtual ya tenían la intención de acceder a la justicia y por ello buscaban la "asesoría de una abogada". Esto evidenció la gran potencialidad de la información que surgía de esos intercambios por WhatsApp, ya que existía una inmediatez ante el conflicto laboral, el cual se presenciaba desde el teléfono celular con mensajes en los que se veía desenvolver los miedos, las disputas, las angustias y las tensiones propias de cuando se pretende iniciar un juicio. 
Si bien la etnografía virtual no supuso el análisis de los perfiles en las redes sociales de las trabajadoras, sí se entró en contacto por páginas como Facebook. Desde allí se podía observar sus interacciones con otras compañeras; e incluso algunas hacían comentarios en las páginas del sindicato, reclamando el aumento de sueldo. Pero para lo que mayormente sirvió la posibilidad de estar comunicadas por esa vía fue para gestionar las contingencias frente a los conflictos. A continuación, se recreará, a modo de ejemplo, algunos de los fragmentos de las conversaciones por WhatsApp. En general, el contacto iniciaba referenciado por otra mujer y se realizaba de la siguiente manera:

05/23/2015, 7:10 PM JBP: "Hola señora XXX soy Julieta. La señora Ester le dejó un mensaje sobre mi situación, por favor si me puede asesorar"

05/23/2015, 7:11 PM VJF: Hola, Julieta sí, me dijo Ester, cuénteme.

05/23/2015, 7:13 PM JBP: Hola, sabe soy la vecina de la señora Ester. Y necesito que me asesore sobre un problema, yo estoy trabajando como empleada doméstica por horas en un departamento. Y ahora mi patrona me quiere poner en blanco. Pero no me quiere reconocer el tiempo que trabajé en negro.

05/23/2015, 7:15 PM VJF: ¿Hace cuánto trabajas ahí?

05/23/2015, 7:17 PM JBP: Hace 5 años y medio...

Después de preguntar sobre sus condiciones generales de trabajo, generalmente se procedía a preguntar por sus problemas actuales. WhatsApp y Facebook se fueron configurando como una herramienta tan útil, que a partir de ellos se obtenía todo tipo de información, se enviaban los audios de las conversaciones que grababan con sus empleadoras o con quienes las atendían en las agencias estatales, así como fotos de sus documentos y de cartas que les solicitaban firmar, etc. Pasado un tiempo las cartas documento y los oficios se enviaron por estos mismos medios, para que ellas gestionaran ante el correo postal público las intimaciones a sus empleadoras. Y de esta misma manera también les enviaba otras instrucciones. Al menos 7 trabajadoras realizaron reclamos laborales por vías virtuales, sin necesidad de acompañamiento presencial. 


\section{Cuadro 7}

\section{Acompañamiento virtual}

\begin{tabular}{|c|c|c|c|c|}
\hline \multicolumn{5}{|c|}{ Acompañamiento virtual } \\
\hline Pseudónimo & $\begin{array}{c}\text { Espacio } \\
\text { al cual se } \\
\text { acompañó } \\
\text { virtualmente }\end{array}$ & $\begin{array}{c}\text { Tiempo } \\
\text { que duró el } \\
\text { acompañamiento }\end{array}$ & $\begin{array}{c}\text { Motivo del } \\
\text { acompañamiento }\end{array}$ & $\begin{array}{c}\text { Observaciones } \\
\text { realizadas en ese } \\
\text { marco }\end{array}$ \\
\hline $\begin{array}{l}\text { Sonia-Para- } \\
\text { guaya }\end{array}$ & $\begin{array}{l}\text { Correo ar- } \\
\text { gentino (en- } \\
\text { vío de carta } \\
\text { documento) }\end{array}$ & Dos semanas & $\begin{array}{l}\text { Intimación a la } \\
\text { registración - } \\
\text { carta documento }\end{array}$ & $\begin{array}{l}\text { Registrada/ sensa- } \\
\text { ción perdida anti- } \\
\text { güedad }\end{array}$ \\
\hline $\begin{array}{l}\text { Karina- Pe- } \\
\text { ruana }\end{array}$ & $\begin{array}{l}\text { Correo ar- } \\
\text { gentino (en- } \\
\text { vío de carta } \\
\text { documento) }\end{array}$ & Tres semanas & $\begin{array}{l}\text { Intimación a la } \\
\text { registración - } \\
\text { carta documento }\end{array}$ & Registrada \\
\hline $\begin{array}{l}\text { Tatiana- Pe- } \\
\text { ruana }\end{array}$ & $\begin{array}{l}\text { Carta } \\
\text { documento- } \\
\text { Correo ar- } \\
\text { gentino }\end{array}$ & Una semana & $\begin{array}{l}\text { Intimación a la } \\
\text { registración- car- } \\
\text { ta documento }\end{array}$ & $\begin{array}{l}\text { Registrada/ sensa- } \\
\text { ción perdida anti- } \\
\text { güedad }\end{array}$ \\
\hline $\begin{array}{l}\text { Carmen- } \\
\text { Paraguaya }\end{array}$ & $\begin{array}{l}\text { Sindicato- } \\
\text { Tribunal- } \\
\text { Abogado }\end{array}$ & Cuatro meses & $\begin{array}{l}\text { Despido por } \\
\text { muerte del em- } \\
\text { pleador }\end{array}$ & $\begin{array}{l}\text { Indignación por par- } \\
\text { te de la familia por } \\
\text { el reclamo, negativa } \\
\text { a pagar.-Abandono } \\
\text { del reclamo }\end{array}$ \\
\hline $\begin{array}{l}\text { Salome- } \\
\text { Peruana }\end{array}$ & $\begin{array}{l}\text { Tribunal - } \\
\text { Abogado }\end{array}$ & Ocho meses & $\begin{array}{l}\text { Despido por } \\
\text { enfermedad de } \\
\text { su hija }\end{array}$ & $\begin{array}{l}\text { Reclamo antigüedad } \\
\text { y empleadora abo- } \\
\text { gada responde a car- } \\
\text { ta documento con } \\
\text { deuda por servicios } \\
\text { jurídicos prestados. }\end{array}$ \\
\hline $\begin{array}{l}\text { Gabriela- } \\
\text { Paraguaya }\end{array}$ & Tribunal & Un año & $\begin{array}{l}\text { Contrato elabora- } \\
\text { do por el Tribu- } \\
\text { nal que descono- } \\
\text { cía vacaciones y } \\
\text { aguinaldo }\end{array}$ & $\begin{array}{l}\text { No vuelve a trabajar } \\
\text { y es intimada por la } \\
\text { empleadora a volver } \\
\text { por abandono de } \\
\text { trabajo }\end{array}$ \\
\hline $\begin{array}{l}\text { Olga- } \mathrm{Pe}- \\
\text { ruana }\end{array}$ & $\begin{array}{l}\text { Carta } \\
\text { documento- } \\
\text { Correo ar- } \\
\text { gentino }\end{array}$ & tres semanas & $\begin{array}{l}\text { Intimación a la } \\
\text { registración- car- } \\
\text { ta documento }\end{array}$ & Registrada \\
\hline
\end{tabular}

El efecto de las "asesorías virtuales" expuso, que se estaba en medio de una transición normativa, con sus consecuencias sociales y las tensiones propias de quienes intentan mantener sus privilegios. En este punto de la indagación y al mirar hacia atrás se entendió que se había participado en el antes, el durante y el después del cambio de una ley, y que esa posibilidad brindaba una rica y profusa 
cantidad de datos para analizar. Además, muchas de las participantes de la investigación habían comprendido que la exigencia de sus derechos era importante, y las posibilidades de registrar sus resistencias, avances y fracasos frente a la justicia mostraron que una forma flexible de investigar se hace necesario cuando se trabaja desde la investigación militante.

\section{CONCLUSIONES}

La investigación militante requiere atención a las trasformaciones del campo, ya que su cometido es precisamente cambiar la realidad, o por lo menos contribuir un poco a ello. Cuando las investigaciones se realizan en escenarios coyunturales, presenciar los cambios normativos y paradigmáticos resulta de gran importancia no sólo como posterior documento histórico, sino también para analizar las posibilidades futuras en la construcción y evaluación de política pública.

Obtener mayor información a medida que se avanzaba en la investigación hizo que se pudiera modificar las técnicas de recolección de información, por ejemplo, cambiar las entrevistas por talleres diagnostico-informativos. Esto con el fin de poder influir en el acceso a la justicia, partiendo del hecho que muchas mujeres no tenían información de qué derechos tenían, ni dónde debían reclamarlos. Por otra parte, también se pudo entender que era necesario realizar estos talleres en zonas fuera de la Ciudad de Buenos Aires, donde se relevó la existencia de una mayor cantidad de mujeres migrantes dedicadas al trabajo en casas particulares, pero quienes finalmente trabajaban en la Ciudad Autónoma de Buenos Aires, por lo que ante un posible juicio deberían recurrir a los tribunales de esta jurisdicción.

Distintas situaciones permitieron llegar a la conclusión que era necesario ser flexible con las premisas iniciales del diseño de la investigación, poniendo en discusión al mismo tiempo las técnicas con las herramientas conceptuales. La flexibilidad en el método también permitió ampliar la muestra, ya que gracias a los talleres diagnostico-informativos se pasó de 9 entrevistas a conocer a 190 mujeres en los talleres diagnóstico-informativo. Por otra parte, en estos talleres se fue poniendo en tensión el concepto de acceso a la justicia, a medida que avanzaba la investigación, lo que no sólo aumentó la cantidad de la información recopilada sino calidad del debate teórico.

Por ello se consideró que la técnica de investigación debe estar atenta a los pedidos del campo, moldearse, ser flexible y acompañar desde un lugar activo, no de simple espectador, ya que las necesidades luchas y vacíos de poblaciones vulnerabilizadas exigen una toma activa de posición. Las posibilidades de modificar la realidad en sociedades tan desiguales como las latinoamericanas son escasas, pero la investigación social en la actualidad se presenta no sólo como necesaria en la construcción de escenarios más inclusivos sino que debe cuestionar el rol de quien investiga en el campo, lo que deja, lo que aporta, no simplemente extraer del sujeto cognoscente (Vasilachis de Gialdino, 2003) elementos de análisis, sino, en ese contacto, transformar la realidad tanto del investigador 
y como la del investigado. Por ello se consideró que la investigación social en la emergencia actual no debe limitarse por el rigor científico, debe poder reinventarse, reevaluar la técnica para concretar la acción que pueda ayudar con la transformación social.

\section{BIBLIOGRAFÍA}

Alonso, Luis Enrique; Benito, Luis Enrique Alonso. La mirada cualitativa en sociología: una aproximación interpretativa. Editorial Fundamentos, 1998.

Ameigeiras, Aldo Rubén (2006). El abordaje etnográfico en la investigación social, en Irene Vasilachis De Gialdino, Estrategias de investigación cualitativa. Barcelona: Gedisa, pp.107-152.

Begala, Silvana y Carlos Lista (2002). "Marginalidad y acceso a la justicia: un estudio empírico en la ciudad de Córdoba", en Cuadernos de fundejus, $\mathrm{N}^{\circ} 6$. Buenos Aires: fundejus, pp. 1-73.

Bhabha, Homi (2013). Nuevas minorías, nuevos derechos: Notas sobre cosmopolitismos vernáculos, $1^{\mathrm{a}}$ ed. Buenos Aires: Siglo XXI editores.

Bourdieu, Pierre y Jean-Claude Passeron (1996). La reproducción: Elementos para una teoría del sistema de enseñanza, $2^{\mathrm{a}}$ ed. México D. F.: Distribuciones Fontamara. Santos,

Boaventura de Sousa, Santos (2009). Sociología jurídica crítica: para un nuevo sentido común en el derecho. Bogotá.

Carbó, Teresa (2001). "El cuerpo herido o la constitución del corpus en análisis de discurso", en Escritos: Revista del Centro de Ciencias del Lenguaje, 23 (enero-junio). Ciudad de México, unam, pp. 17-47 [disponible en línea]: <http://cmas.siu.buap.mx/ portal_pprd/work/sites/escritos/resources/LocalContent/31/1/carbo.pdf >. [Consultado el 28/05/2017.]

Chihu Amparán, Aquiles y López Gallegos, Alejandro. (2007). La construcción de la identidad colectiva en Alberto Melucci. Polis, 3(1), 125-159. Recuperado en 07 de junio de 2020, de http://www.scielo.org.mx/scielo.php?script=sci arttext\&pid=S18 $7023332007000100006 \& \operatorname{lng}=\mathrm{es} \& \operatorname{tlng}=\mathrm{es}$.

Domínguez Figaredo, Daniel et al. (2007). - Virtual Ethnographyll, en Forum Qualitative Sozialforschung / Forum: Qualitative Social Research, 8 (3). Berlín: Freie Universität [disponible en línea]: <http://www.qualitativeresearch.net/index.php/fqs/ article/view/274/603>. [Consultado el 04/06/2017.]

Fraser, Nancy (2006). - Reinventar la justicia en un mundo globalizadoll, en New Left Review [edición en español], vol. 36. Madrid: Traficantes de sueños, pp. 31-50.

Fraser, Nancy (1989). Unruly Practices: Power, Discourse, and Gender in Contemporary Social Theory. Minneapolis: University of Minnesota Press.

Fals Borda, Orlando (1990) El Tercer Mundo y la reorientación de las ciencias contemporáneas. En Nueva Sociedad Nro.107. Mayo- junio 1990, PP. 83-91

Hine, Christine (2000). Virtual Ethnography. Londres: SAGE.

Hanisch, Carol. (2016). Lo personal es político. A. Franulic y I. Jeka (compiladoras). Lo personal es político. s/l, Ediciones feministas lúcidas. Recuperado de http://www. diariofemenino. com. ar/documentos/lo-p ersonal-es-politico_final. pdf. 
IOÉ, Colectivo (2010). ¿Para qué sirve el grupo de discusión?: Una revisión crítica del uso de técnicas grupales en los estudios sobre migraciones. EMPIRIA. Revista de Metodología de Ciencias Sociales. N.o 19, enero-junio, 2010, pp. 73-99

Gallinati, Carla (2014). Migración, vivienda e integración regional: Un abordaje desde la villa miseria. (Tesis de doctorado.) Facultad de Ciencias Sociales, Universidad de Buenos Aires [disponible en línea]: <https://www.academia.edu/14929708/MIGRACIÓN_VIVIENDA_E_INTEGRACIÓN_EGIONAL_Un_abordaje_desde_la_villa_miseria>. [Consultado el 26/05/2017.]

García Villegas, Mauricio (director) (2010). Normas de papel. La cultura del incumplimiento. Bogotá: Siglo del Hombre Editores.

Grosfoguel, Ramón (2012). El concepto de «racismo» en Michel Foucault y Frantz Fanon: ¿teorizar desde la zona del ser o desde la zona del no-ser?, en Tabula Rasa, vol. 16. Bogotá: Universidad Colegio Mayor de Cundinamarca, pp. 79-102.

Mezzadra, Sandro y Brett Neilson (2017) La frontera como método. Traficantes de sueños.

Melucci, Alberto (2018) Acción colectiva, vida cotidiana y democracia. Biblioteca Virtual Miguel de Cervantes. Recuperado en 04 de enero de 2020, de http://www.cervantesvirtual.com/nd/ark:/59851/bmc0924292

Melucci, Alberto. (1988). Las teorías de los movimientos sociales. Estudios políti$\cos , 5(2)$.

Novick, Susana (2008). "Migración y políticas en Argentina: Tres leyes para un país extenso (1876-2004)", en Susana Novick (comp. y con la colabor. de Carolina Stefoni y Alfonso Hinojosa Gordonava), Las migraciones en América Latina: políticas, culturas y estrategias. Buenos Aires: Catálogos-clacso.

Novick, Susana (2014). Cómo trabajar con textos jurídicos en ciencias sociales, documento de trabajo N. ${ }^{\circ}$ 69. Buenos Aires: Instituto de Investigaciones Gino Germani, Facultad de Ciencias Sociales, Universidad de Buenos Aires.

Poblete, Lorena (2015). La producción de estándares laborales para el trabajo doméstico. CLACSO.

Santos, Boaventura de Sousa (2009). Sociología jurídica crítica: para un nuevo sentido común en el derecho. Bogotá: Trotta-ILSA.

Stavenhagen, Rodolfo (2015). Etnografía activista: mi experiencia en la ONU. Nueva antropología, 28(83), 13-24. Recuperado en 12 de julio de 2018, de http://www. scielo.org.mx/scielo.php?script=sci arttext\&pid=S018506362015000200002\&lng= es\&tlng=es.

Spradley, James P. (1979). The Ethnographic Interview. Nueva York: Holt, Rinehart and

Winston.

Vasilachis de Gialdino, Irene (2003). Pobres, pobreza, identidad y representaciones sociales. Barcelona: Gedisa.

Weckesser, Cintia (2010). Reflexiones acerca del quién y el cómo de la Justicia en la era poswesfaliana a partir de algunos aportes de Pierre Bourdieu y Jacques Ranciére, en Patricia MOREY y Adriana BORA, Teoría social y género: polémicas en torno al modelo teórico de Nancy Fraser, Buenos Aires: Catálogos.

Wimmer, Andreas y Nina Glick Schiller (2002). Methodological Nationalism and Beyond: Nation-State Building, Migration and the Social Sciences $\bigotimes$, in Global Networks, vol. 2 (4), pp. 301-324. 